\title{
Macaco-Prego, como controlar esta nova praga florestal?
}

\author{
V ALMIR JosÉ Rocha
}

Palavras chaves: praga florestal, Cebus apella, Pinus spp.;

\section{INTRODUÇÃO}

O macaco-prego é a espécie de primata que apresenta maior distribuição geográfica entre as espécies neotropicais, ocorrendo desde o norte da Colômbia (com possibilidade de ocorrência ao sul da América Central) até o sul da Argentina, sendo limitado à oeste pela Cordilheira dos Andes e a leste pelo oceano Atlântico (HILL, 1960).

Esse primata é encontrado nos mais diferentes tipos de florestas ao longo de sua distribuição. Vive em grupos estáveis, com organização social de machos e fêmeas apresentando alta coesão entre os membros do grupo (IZAWA, 1980; ESCOBAR-PÁRAMO, 1989). Os grupos apresentam números de integrantes variando entre 6 a 30 indivíduos sempre liderados por um macho dominante (FREESE \& OPPENHEIMER, 1981).

Devido à sua dieta onívora, o macaco-prego é uma espécie com grande capacidade de adaptação aos ambientes alterados pelo homem. Sobrevive em áreas de florestas fragmentadas, mínimas e degradadas desde que tenham acesso a plantações ao redor de seu ambiente (ROCHA, 1992). E é justamente nessa situação que essa espécie é vista como uma praga por produtores rurais, pois invadem plantações e passam a consumir pomares, milharais, canaviais e até mesmo plantações de Pinus spp.

Nesta última, encontram um recurso alimentar abundante e disponível o ano todo que é a resina do Pinus. Os primatas atacam quase sempre o terço superior da árvore, causando às vezes um anelamento pela retirada da casca, conseqüentemente esta parte seca e posteriormente, cai principalmente pela ação do vento. A ação dos animais se agrava principalmente durante a estiagem, quando ocorre uma menor oferta de seus alimentos naturais (PIZANI, 1997). 
Outra constatação importante é que, além do prejuízo causado à árvore, a ação dos primatas, também pode aumentar a possibilidade de ocasionar um acidente de trabalho pela queda dos ponteiros nos operários durante o corte da madeira (PIZANI, 1997).

Os problemas mencionados acima são graves, e na tentativa de solucioná-los é imprescindível responder uma questão básica que é: Por que essa espécie de primata esta se alimentando de resina de Pinus sp.? detalhes:

Três hipóteses são formuladas e precisam ser investigadas em

1. Os animais são atraídos aos Pinus devido à alta palatabilidade da resina;

2. Existe uma escassez de recursos naturais forçando os animais a procurar novas fontes de alimentos;

3. Existe um aumento populacional dos macacos devido à ausência de predadores e alta disponibilidade de recursos.

Neste trabalho foram feitas propostas para controlar ou minimizar os ataques de Cebus apella em reflorestamento de Pinus spp.

As propostas para o controle dos macacos-pregos nas plantações de Pinus envolvem melhoramentos genéticos de Pinus, manejo das áreas com Pinus e das área nativas e o manejo dos animais.

Quanto ao melhoramento genético das plantas, é importante que se busque o desenvolvimento de novas variedades que produzam resina impalatável para Cebus apella.

- QUANTO AO MANEJO DAS ÁREAS, AS PRINCIPAIS MEDIDAS A SEREM TOMADAS SÃO:

- Manter em dia o desbaste dos Pinus.

- Fazer aceiros para evitar pontes naturais (galhos) entre a área de Pinus e a área de floresta nativa.

- Criar barreiras de proteção às florestas de Pinus com outras culturas, tais como eucaliptos e araucárias, ou outras espécies que não sejam de interesse do animal.

- Quando possível fazer a substituição do Pinus por outras espécies (Ex.: eucaliptos).

- Avaliar a disponibilidade de recursos naturais para Cebus apella para verificar se existe a necessidade de se fazer um enriquecimento ambiental, com espécies nativas utilizadas pelos animais.

- Reintrodução de predadores naturais.

- QUANTO AO MANEJO DOS ANIMAIS, ENVOLVE-SE MÉTODOS QUE VISAM O CONTROLE POPULACIONAL ATRAVÉS DE: 
- Vasectomização dos machos dominantes. Esse método é importante, pois, os animais não perdem sua posição hierárquica dentro do grupo e continuam copulando.

- Translocação de grupos problemas ou parte destes para outras áreas.

- ENTRETANTO PARA QUE SE POSSA REALIZAR O MANEJO DOS ANIMAIS É NECESSÁRIO A REALIZAÇÃO DE ALGUNS ESTUDOS PRÉVIOS TAIS COMO:

- Acompanhamento dos animais para que se possa escolher o melhor local para a realização de capturas e determinar quais e quantos indivíduos deverão ser capturados;

- Realizar estimativas populacionais de Cebus apella na área.

- Determinar as estratégias alimentares dos animais sobre Pinus.

- Determinar se existe a presença de predadores naturais.

- Realizar estimativas do prejuízo causado pelos animais.

- Encontrar uma nova área de floresta preferencialmente sem a presença de Cebus apella, com condições de abrigar os animais que serão translocados.

Todos os métodos exigem a necessidade de especialistas, para que ocorra sucesso na sua realização e preserve à integridade dos animais manejados, pois como espécime da fauna brasileira, Cebus apella é uma espécie protegida por lei .

\section{DISCUSSÃO}

Apesar da relação macaco-prego x Pinus ser antiga, com relatos por parte dos produtores rurais de ataques às plantações de Pinus na década de 1950, nos últimos 10 anos os ataques tem se intensificado (obs. pess.). Tal fato pode estar relacionado com as três hipóteses levantadas neste trabalho. Uma grande preocupação é a hipótese da alta palatabilidade, pois se os animais passaram a se alimentar da resina e apreciaram, ocorre um aprendizado que é transmitido para as próximas gerações. Esse comportamento peculiar de transmissão de conhecimento é denominado "pré-cultura", adquirido devido às situações do ambiente que levam os animais a buscarem novas fontes de alimentos, que normalmente não seriam utilizadas (IZAWA \& MIZUNO, 1977; ROCHA et. A.l., 1998).

Quanto ao manejo dos animais, estudos anteriores onde a translocação foi testada (Rocha 1992) em uma área onde 22 indivíduos de Cebus apella causava danos a plantações e experimentos da Fazenda Escola da Universidade Estadual de Londrina, 14 foram retirados. Atualmente o grupo restante na área de floresta da Universidade se encontra com 14 indivíduos e os resultados 
obtidos demonstraram ser satisfatórios mesmo 9 anos após a translocação, porém como não foi realizado a vasectomização dos machos dominantes, o grupo poderá se restabelecer em longo prazo, ocasionando novamente os problemas, Todavia, as vantagens desse método são: baixo custo, realização em curto prazo, os resultados são imediatos e é ideal para grupos mansos. Uma desvantagem do método é a dificuldade de se encontrar áreas com condições adequadas para receber os animais translocados.

Ë importante que se comente que todas as propostas sugeridas acima são passíveis de serem testadas em relação a reflorestamento de Pinus. Entretanto fica claro que a associação de vários métodos é a melhor estratégia a ser adotada na busca de soluções para esse problema.

Acreditamos que existe a necessidade urgente de se realizar mais estudos para que se possa desenvolver e planejar um maior número de medidas que venham a solucionar o problema causado por mais essa nova praga florestal, mas que também venham de encontro a interesses preservacionistas para Cebus apella.

\section{BIBLIOGRAFIA}

FREESE, C.H.; OPPENHEIMER, J.R. 1981. The capuchin monkeys, genus Cebus In: COIMBRA-FILHO, A.F.; MITTERMEIER, R.A. Ecology and behavior of neotropical primates. Academia Brasileira de Ciências, Rio de Janeiro-RJ, v.1, p.1-496.

ESCOBAR-PARAMO, P. 1989. Social Relations Between Infants and Other Group Members in the Wild Black-Capped Capuchin (Cebus apella). Field studies of new world monkeys, La Macarena Colombia, v.2, p.57-63.

HILL, W.C.O. 1960. Primates; Comparative Anatomy and Taxonomy. Edinburgh University Press, Edinburgh, v. IV.

IZAWA, K \& MIZUNO, A. 1977. Palm fruit cracking behavior of wild blackcapped capuchin (Cebus apella). Primates. v.18, 773-792.

IZAWA, K. 1980. Social Behavior of the Wild Black-Capped Capuchin (Cebus apella). Primates, v.31, p.443-467.

PIZANI, A. J. 1997. Alerta sobre os riscos de acidentes ocasionados pelo ataque de macaco-prego (Cebus apella) em floresta de Pinus spp.: Estudo de casos. Monografia. Setor de Ciências Agrárias - Escola de Florestas. Universidade Federal do Paraná. Curitiba -Pr.

ROCHA, V.J. 1992. Desenvolvimento de um método de manejo envolvendo um grupo de macacos-pregos (Cebus apella) em condição semi-selvagem no Horto Florestal da UEL, Londrina-Pr. Monografia (Zooecologia)- Centro de Ciências Biológicas, Universidade Estadual de Londrina. Londrina-Pr.

ROCHA,V.J; REIS, N. R \& SEKIAMA, M.L "Uso de ferramentas por Cebus apella (Linnaeus) (Primates, Cebidae) para obtenção de larvas de coleoptera 
que parasitam sementes de Syagrus romanzoffianum (Cham.) Glassm. (Arecaceae)", Revista Brasileira de Zoologia 15(4): 945-950, 1998. 